\title{
TINGKAT KEMAMPUAN SERVIS PENDEK FOREHAND DAN KEMAMPUAN SMASH SISWA PESERTA EKSTRAKULIKULER BULUTANGKIS SLB NEGERI I KOTA BENGKULU
}

$\sqrt{\mathbf{D} P}$

\author{
Bambang Irawan ${ }^{1, a)}$, Supriyantof ${ }^{1}$ \\ 1)Program studi Pendidikan Jasmani Universitas Dehasen Bengkulu \\ a)Corresponding Author: bambangitrawan@gmail.cm
}

\begin{abstract}
The correct serve and smash technique skills in the badminton game of students at SLB N 1 in Bengkulu city is unknown. This study aims to determine the level of short forehand serve and smash skills of students participating in badminton extracurricular at SLB N 1 in Bengkulu City.This research is a quantitative descriptive study with a survey method. The instruments used were a short forehand service test and a badminton smash test. The subjects in this study were all students of badminton extracurricular activities, totaling 20 students. The data analysis technique used in this study was descriptive statistics with a percentage formula.The results of the research on short forehand serveskills of the participants in badminton extracurricular activities at SLB $N 1$ in Bengkulu city were very good categories of $0 \%$, good categories of $0 \%$, moderate categories of $0 \%$, lack of 14 students or $70 \%$, and the students which falls into the category of less than 6 students or $30 \%$. The smash skillwas very good at $0 \%$, the good category was $0 \%$, the medium category was $0 \%$, the category was less than 7 students or 35\%, and the students were categorized as less 13 students or $65 \%$.
\end{abstract}

Keywords: Short Forehand Serve, Badminton Smash

Tujuan penelitian ini untuk mengetahui hubungan power otot tungkai terhadap keterampilan shooting futsal di SMP Negeri 15 Kota Bengkulu. bahwa keterampilan shooting para siswa kurang maksimal sehingga pada shooting bola jarang masuk ke gawang lawan. Masalah ini disebabkan oleh beberapa faktor, antara lain rendahnya tingkat power otot tungkai siswa SMP Negeri 15 Kota Bengkulu. Metode penelitian ini adalah metode korelasional. Populasi penelitian ini seluruh pemain futsal SMP 15 sebanyak 20 orang sedangkan pengambilan sampel menggunakan teknik total sampling, Tempat pelaksanaan penelitian di lapangan SMP 15 Kota Bengkulu, adapun waktu penelitian adalah bulan maret 2019. Data power otot tungkai diambil dengan tes vertical jump, dan data keterampilan shooting diambil dengan tes shoot ke gawang. Teknik analisis data penelitian ini menggunakan teknik dengan analisis korelasi. Hasil analisis data menunjukkan bahwa: Terdapat hubungan yang signifikan antara power otot tungkai (X) terhadap keterampilan shooting pada siswa futsal di SMP 15 Kota Bengkulu, dengan nilai $r_{x y}=0,92>r_{(0,05)(19)}=0,444$

\section{Kata kunci : Power Otot Tungkai, Keterampilan shooting}

\section{Pendahuluan}

Pendidikan sangat penting dalam kehidupan manusia karena dengan adanya pendidikan diharapkan manusia dapat mengembangkan pengetahuan, keterampilan dan kreativitasnya. Keberhasilan dalam bidang pendidikan sangat ditentukan oleh keberhasilan dalam proses pembelajaran.
Proses pembelajaran merupakan serangkaian interaksi antara manusia yaitu yang mengajar atau yang biasa disebut guru dengan orang yang diajar atau siswa.

Program pembelajaran di Indonesia terdapat tiga program, yaitu: program intrakurikuler, kokurikuler, dan program ekstrakurikuler. Menurut Yudha M. Saputra (1998: 6-7) 
menjelaskan bahwa kegiatan intrakurikuler adalah program pengajaran yang tersusun berupa label mata pelajaran, penjatahan waktu, dan penyebarannya di setiap kelas dan satuan pelajaran. Kegiatan ekstrakurikuler adalah kegiatan di luar jam pelajaran biasa, yang bertujuan agar siswa lebih memperdalam dan lebih menghayati apa yang dipelajari pada kegiatan intrakurikuler. Ekstrakurikuler adalah kegiatan yang dilakukan siswa sekolah atau universitas di luar jam belajar kurikulum standar.

Pada prinsipnya tujuan pembelajaran Pendidikan Jasmani Olahraga dan Kesehatan di sekolah membantu peserta didik dapat meningkatkan kemampuan dan keterampilan gerak dasar. Akan tetapi dengan melihat kenyataan yang ada, bahwa Pendidikan Jasmani Olahraga dan Kesehatan yang hanya 2 (dua) jam pelajaran perminggu diperkirakan belum memenuhi apa yang dinginkan untuk mencapai tujuan Pendidikan Jasmani Olahraga dan Kesehatan. Ekstrakurikuler olahraga merupakan salah satu solusi untuk dapat mencapai tujuan Pendidikan Jasmani. Jika kegiatan ekstrakurikuler dilaksanakan dengan baik, terencana dan berkesinambungan diharapkan dapat meningkatkan keterampilan.

Pelaksanaan kegiatan pembelajaran siswa diarahkan untuk mempelajari macam-macam materi olahraga sesuai dengan kurikulum yang dilaksanakan oleh sekolah. Kegiatan pembelajaran yang dilaksanakan di sekolah terbagi menjadi beberapa macam-macam sebagai contoh yaitu permainan bola besar, bola kecil, permainan target, aktivitas ritmik, senam kelentukan dll. Kegiatan pembelajaran olahraga yang dilaksanakan oleh sekolah untuk melaksanakan program pembelajaran yang disesuaikan dengan kurikulum. Selain kegiatan pembelajaran secara intrakurikuler siswa juga dapat mengikuti pengayaan dengan mengikuti ekstrakurikuler dapat membantu meningkatkan pertumbuhan dan perkembangan siswa serta siswa juga dapat memperdalam dan memperluas pengetahuan yang berkaitan dengan keterampilan masingmasing cabang olahraga, pembentukan nilai- nilai kepribadian siswa serta memunculkan bakat siswa yang berprestasi dalam bidangnya.

Manusia diciptakan di dunia mempunyai hak asasi manusia (HAM) yang sama. Demikian juga dalam memperoleh pendidikan, pendidikan khusus merupakan bagi peserta didik yang memiliki tingkat kesulitan dalam mengikuti proses pembelajaran karena kelainan fisik, emosioanal, mental, sosial, dan memiliki potensi kecerdasan dan bakat istimewa (UU RI tentang SISDIKNAS tahun 2003 pasal 32 (1) dalam Bandi Delphie, 2007: 147).

Tidak semua anak dilahirkan dalam keadaan sempurna, ternyata ada sebagian kecil yang mengalami kelainan sehingga mengalami hambatan-hambatan baik dalam perkembangan fisik maupun dalam perkembangan mentalnya. Anak yang demikian diklasifikasikan sebagai anak luar biasa. Seperti anak yang lain, anak-anak luar biasa juga merupakan bagian dari generasi yang harus memperoleh kesempatan untuk mengembangkan dirinya sesuai dengan potensi yang dimilikinya. Perlu diingat bahwa anak cacat juga merupakan anak bangsa yang dapat tumbuh dan berkembang menjadi dewasa yang mempunyai percaya diri dan harga diri yang tinggi dalam memimpin dan mengabdikan dirinya untuk bangsa dan negara pada masa yang akan datang.

Sekolah luar biasa (SLB) Negeri 1 Kota Bengkulu merupakan salah satu SLB di Kota Bengkulu yang peduli terhadap pentingnya pendidikan bagi anak luar biasa terutama bagi anak tuna grahita, tuna rungu dan tuna daksa. Selain itu SLB Negeri 1 Kota Bengkulu juga mempunyai prestasi yang sangat baik dibidang pendidikan maupun non pendidikan. Pendidikan bagi anak sekolah luar biasa sangat penting karena mereka mempunyai tingkat inteligensi dibawah ratarata anak normal, dengan demikian pendidikan bagi anak sekolah luar biasa memerlukan kurikulum, tenaga pendidik, dan sarana-prasarana yang khusus yang telah disesuaikan dengan tingkat kecacatannya. 
Selain itu guru juga harus memperhatikan faktor-faktor pertumbuhan dan perkembangan anak, kemampuan guru, terbatasnya sarana dan prasarana serta pengembangan cabang olahraga, masalahmasalah kesehatan sesuai situasi dan kondisi setempat sehingga bisa memupuk bakat serta minat yang dimiliki anak penyandang cacat. Olahraga yang diberikan pada anak tunagrahita merupakan suatu alat untuk membantu mereka dalam melanjutkan kelangsungan hidupnya, setidaknya mereka dapat membentuk untuk dirinya.

Kegiatan ekstrakurikuler yang diselenggarakan di SLB Negeri 1 Kota Bengkulu bermacam-macam. Kegiatan tersebut ada yang berorientasi di bidang olahraga, Pramuka dan lain-lainya. Peserta didik diwajibkan memilih salah satu kegiatan ekstrakurikuler sesuai dengan bakat dan minat. Adapun kegiatan ekstrakurikuler dalam bidang olahraga yang diselenggarakan di SLB Negeri 1 Kota Bengkulu antara lain adalah tenis meja, bola voli, dan bulutangkis. SLB Negeri 1 Kota Bengkulu memiliki sarana dan prasarana yang cukup memadai, Dalam prestasinya sangat bagus dan tidak kalah bersaing dengan sekolah SLB lain dalam bidang olahraga, khususnya bulutangkis di kota Bengkulu. Kegiatan ekstrakurikuler bulutangkis di SLB Negeri 1 Kota Bengkulu lebih banyak dilakukan melalui latihan dalam bentuk permainan dengan pemberian teknik dasar. Kegiatan ekstrakurikuler bulutangkis di SLB Negeri 1 Kota Bengkulu diikuti oleh 20 siswa. Dalam kegitan latihan masih banyak siswa yang mempunyai teknik dasar bermain bulutangkis yang kurang baik. Kemampuan siswa dalam melakukan teknik dasar bulutangkis masih sering menemui kesalahan seperti servis yang tidak sampai, dalam melakukan smash bola tidak bergerak menukik ke bawah dengan keras dan bahkan bola melaju horizontal dan keluar lapangan. Teknik dasar merupakan hal yang penting dalam suatu cabang olahraga bulutangkis, karena teknik dasar akan menentukan cara melakukan suatu gerakan dasar yang baik.
Permasalahan yang muncul pada saat kegiatan pembelajaran Pendidikan Jasmani khususnya bulutangkis di SLB Negeri 1 Kota Bengkulu adalah belum diketahui secara pasti kemampuan dan keterampilan dari masingmasing siswa dalam bermain bulutangkis, sehingga dari hal tersebut perlu adanya sebuah penelitian yang meneliti dan membahas tentang keterampilan bermain bulutangkis yang ada di dalam kegiatan pembelajaran penjas dengan materi bulutangkis SLB Negeri 1 Kota Bengkulu.

Mengingat bahwa dalam pembelajaran bulutangkis di SLB Negeri 1 Kota Bengkulu hanya diberikan teknik dasar saja dan tidak ada program latihan 4 komponen-komponen fisik, Sehingga menyebabkan perbedaan keterampilan khususnya kemampuan dasar yang sering dilakukan dalam permainan bulutangkis pada siswa di SLB Negeri 1 Kota Bengkulu tersebut maka perlu ditelusuri faktor penyebabnya, apakah karena dalam kegiatan pembelajaran di SLB Negeri 1 Kota Bengkulu hanya menekankan pada permainan saja dan tidak diberikan berbagai teknik dengan benar, untuk itu perlu diadakan penelitian, tentang tingkat kemampuan servis pendek dan kemampuan smash pada permainan bulutangkis di kegiatan ekstrakurikuler SLB Negeri 1 Kota Bengkulu

Untuk mengetahui hal tersebut maka perlu dilakukan penelitian dengan judul "Tingkat kemampuan servis pendek forehand dan kemampuan smash siswa peserta ekstrakurikuler bulutangkis SLB Negeri 1 Kota Bengkulu”.

Bulutangkis atau badminton adalah suatu olahraga bola kecil yang dimainkan dengan menggunakan raket untuk memukul shuttlecock di lapangan permainan dibatasi oleh net. Bulutangkis merupakan permainan yang bersifat individual yang dimainkan oleh dua orang (untuk tunggal) atau dua pasangan (untuk ganda) yang saling berlawanan. Bulutangkis bertujuan memukul bola atau shuttlecock melewati jaring (net) agar jatuh di bidang permainan lawan yang sudah ditentukan dan berusaha mencegah lawan melakukan hal yang sama. 
Menurut M.L Johnson (1984: 10), permainan bulutangkis adalah shuttlecock yang harus dipukul dengan raket melampaui net ke lapangan lawan. Sebaliknya lawan harus mengembalikan cock dengan pukulan raketnya agar tidak jatuh dilapangannya sendiri. Apabila shuttlecock jatuh dilantai atau menyangkut di net maka permainn berhenti (Herman Subardjah, 2000: 13).

\section{Hakikat Ekstrakurikuler Bulutangkis}

Berdasarkan Surat Keputusan (SK) Mentri Pendidikan Dan Kebudayaan, No 0461/U/1964 dan SK Direktur Jendral Pendidikan Dasar dan Menengah Nomor: 226/C/Kep/O/1992, kegiatan ekstrakurikuler merupakan jalur pembinaan kesiswaan di samping jalur Organisasi Siswa Intra Sekolah (OSIS) latihan kepemimpinan wawasan wiyatamadya.

Menurut Yudha M Saputra (1990: 6) ekstrakurikuler adalah kegiatan di luar jam pelajaran sekolah biasa, yang di lakukan di sekolah maupun di luar sekolah dengan tujuan untuk memperluas pengetahuan siswa, mengenai hubungan antar mata pelajaran, menyalurkan bakat dan minat, serta melengkapi pembinaan manusia seutuhnya.

\section{Ekstrakurikular Bulutangkis di SLB}

\section{Negeri I Kota Bengkulu}

SLB Negeri 1 Kota Bengkulu yang berlokasi di Kota Bengkulu, adalah salah satu sekolah yang menyelenggarakan kegiatan ekstrakurikuler bulutangkis. Kegiatan eksterakulekuler yang dilaksanakan dua kali dalam seminggu, dan dilaksanakan pada hari hari rabu dan jum'at. Kegiatan eksterakurikuler dilaksanakan dalam waktu 180 menit, dan dimulai jam 15.00 sampai dengan 18.00 WIB.

Kegiatan eksterakurikuler bulutangkis difasilitasi sarana dan prasarana meliputi: lapangan, shutlecook, dan net serta satu pelatih bulutangkis yang diampu oleh salah satu guru pendidikan jasmani olahraga dan kesehatan. Ekstrakurikuler bulutangkis di SLB Negeri 1 Kota Bengkulu banyak di ikuti oleh siswa/siswi

\section{Metode Penelitian}

Penelitian ini adalah penelitian deskriptif kuantitatif yaitu tentang tingkat kemampuan servis pendek forehand dan kemampuan smash bulutangkis siswa peserta ekstrakurikuler SLB Negeri I Kota Bengkulu. Dalam penelitian ini peneliti hanya ingin mengetahui tingkat kemampuan servis pendek forehand dan kemampuan smash bulutangkis siswa peserta ekstrakurikuler SLB Negeri I Kota Bengkulu.

\section{Populasi dan Sampel Penelitian}

Populasi adalah wilayah generalisasi yang terdiri atas objek/subjek yang mempunyai kuantitas dan karakteristik tertentu yang ditetapkan oleh peneliti untuk dipelajari dan kemudian ditarik kesimpulannya (Sugiyono, 2009:297). Populasi dalam penelitian ini adalah seluruh siswa peserta ekstrakurikuler bulutangkis SLB Negeri I Kota Bengkulu yang berjumlah 20 siswa.

Sampel adalah bagian dari jumlah dan karakteristik yang dimiliki oleh populasi tersebut (Sugiyono, 2009: 118). Dikarenakan jumlah populasi yang digunakan dalam penelitian ini, maka seluruh populasi dijadikan sebagai sampel penelitian sehingga disebut sebagai sampel populasi. Jumlah sampel yang digunakan adalah 20 siswa, yang seluruhnya adalah siswa peserta ekstrakurikuler bulutangkis SLB Negeri I Kota Bengkulu

\section{Hasil Penelitian}

Untuk mengidentifikasi kecenderungan kemampuan servis pendek forehand dan kemampuan smash bulutangkis dilakukan dengan pengkategorian menjadi lima kategori yaitu baik sekali, baik, sedang, kurang, dan kurang sekali. Hasil analisis terhadap kemampuan servis pendek forehand dan kemampuan smash bulutangkis siswa peserta ekstrakurikuler bulutangkis SLB Negeri I Kota Bengkulu dapat diuraikan sebagai berikut :

\section{Servis Pendek Forehand}

Untuk mengidentifikasi kecenderungan Servis pendek forehand dilakukan dengan pengkategorian menjadi lima kriteria yaitu baik sekali, baik, sedang, kurang, dan kurang sekali. Perhitungan kecenderungan mengenai Servis pendek forehand dapat dilihat pada tabel berikut ini:

\section{Tabel 2. Servis Pendek Forehand}

\begin{tabular}{|c|c|c|c|c|}
\hline No & Nilai & Kategori & Jumlah & Persentase \\
\hline 1 & $>80$ & Baik Sekali & 0 & 0 \\
\hline 2 & $66,67-80$ & Baik & 0 & 0 \\
\hline 3 & $53,33-66,67$ & Sedang & 0 & 0 \\
\hline 4 & $40-53,3$ & Kurang & 14 & 70 \\
\hline 5 & $\leq 40$ & Kurang Sekali & 6 & 30 \\
\hline & & & 20 & $100 \%$ \\
\hline
\end{tabular}


Dari tabel diatas, tampak bahwa Servis pendek forehand peserta ekstrakurikuler bulutangkis siswa peserta ekstrakurikuler SLB Negeri I Kota Bengkulu adalah kategori baik sekali sebesar $0 \%$, kategori baik sebesar $0 \%$, kategori sedang sebesar $0 \%$, kategori kurang sebanyak 14 siswa atau sebesar $70 \%$, dan siswa yang masuk kedalam kategori kurang sekali sebanyak 6 siswa atau sebesar $30 \%$.

Berdasarkan perhitungan di atas maka dapat disimpulkan bahwa Servis pendek forehand peserta ekstrakurikuler bulutangkis masuk dalam kategori sedang sebanyak 8 siswa atau dengan persentase $40 \%$. Hal ini dapat diperjelas dengan histogram di bawah ini:

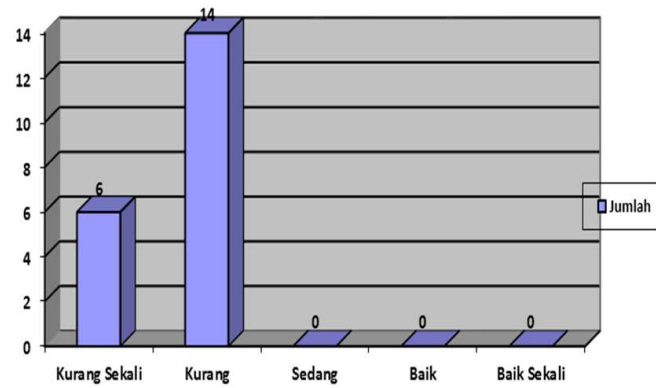

Gambar 11. Diagram Batang Servis

\section{Pendek Forehand Smash}

Untuk mengidentifikasi smash dilakukan dengan pengkategorian menjadi lima kriteria yaitu baik sekali, baik, sedang, kurang, dan kurang sekali. Perhitungan mengenai smash dapat dilihat pada tabel berikut ini:

\section{Tabel 3. Smash}

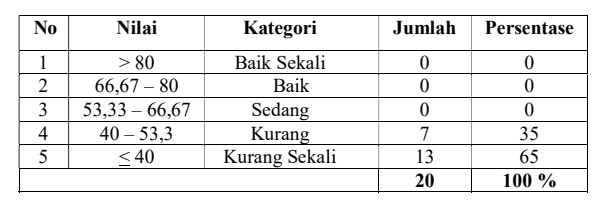

Dari tabel diatas, tampak bahwa smash peserta ekstrakurikuler bulutangkis siswa SLB Negeri I Kota Bengkulu adalah kategori baik sekali sebesar $0 \%$, kategori baik sebesar $0 \%$, kategori sedang sebesar $0 \%$, kategori kurang sebanyak 7 siswa atau sebesar $35 \%$, dan siswa yang masuk kedalam kategori kurang sekali sebanyak 13 siswa atau sebesar $65 \%$.
Berdasarkan perhitungan di atas maka dapat disimpulkan bahwa smash peserta ekstrakurikuler bulutangkis masuk dalam kategori sedang sebanyak 8 siswa atau $40 \%$. Hal ini dapat diperjelas dengan histogram di bawah ini:

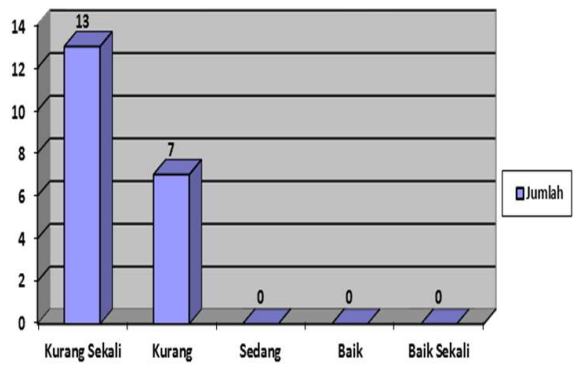

\section{Gambar 12. Diagram Batang Smash \\ Pembahasan}

Berdasarkan analisis kemampuan servis pendek forehand dan kemampuan smash bulutangkis siswa peserta ekstrakurikuler bulutangkis SLB Negeri I Kota Bengkulu, dengan tes kemampuan servis pendek forehand bulutangkis sebagian besar memiliki kategori kurang sebanyak 14 siswa (70\%). Hasil tersebut dapat diartikan bahwa kemampuan servis pendek forehand siswa peserta ekstrakurikuler bulutangkis SLB Negeri I Kota Bengkulu adalah kurang. Sedangkan kemampuan smash bulutangkis sebagian besar memilliki kategori kurang sekali sebanyak 13 siswa (65\%). Hasil tersebut dapat diartikan bahwa kemampuan smash siswa peserta ekstrakurikuler bulutangkis SLB Negeri I Kota Bengkulu adalah kurang sekali.

Merujuk dari hasil penelitian dan kesimpulan dapat dijelaskan bahwa keterampilan servis pendek forehand dan kemampuan smash bulutangkis dalam kategori kurang. Hal ini dipengaruhi oleh beberapa sebab diantaranya yaitu kondisi aktifitas yang dilakukan siswa sebelumnya sehingga dapat mempengaruhi kondisi fisik pada saat diambil datanya. Atau pola latihan yang tidak terkontrol sebelumnya sehingga hasil yang diharapkan tidak sesuai dengan yang didapatkan pada saat diukur atau saat diambil datanya.

Hasil penelitian keterampilan servis pendek forehand dan kemampuan smash 
bulutangkis, jika dilihat dengan kondisi sarana dan prasarana olahraga, kondisi sarana dan prasarana yang cukup mendukung, sehingga siswa yang mengikuti ekstrakurikuler Bulutangkis cukup dapat menggunakan fasilitas yang cukup lengkap.

Faktor yang mempengaruhi servis pendek forehand dan kemampuan smash siswa peserta ektrakurikuler bulutangkis SLB Negeri I Kota Bengkulu diantaranya sebagai berikut:

\section{Faktor Siswa}

Siswa merupakan subjek belajar, sehingga segala bentuk aktifitas fisik mungkin tidak terkontrol, banyaknya aktifitas yang dilakukan siswa akan membuat kondisi fisik berubah-ubah sehingga hasil penelitian mungkin tidak akan sesuai seperti yang diharapkan, namun peneliti selalu berusaha untuk mendapatkan hasil yang maksimal dan yang sebenar-benarnya.

2. Faktor Guru, Pembina Ekstrakurikuler

Dalam proses belajar mengajar, seorang guru memiliki tugas yang amat penting. Sehingga guru Pembina hendaknya memberikan bentuk latihan fisik yang sesuai dengan takaran anak SLB sehingga melihat dari hasil diatas dapat diuraikan bahwa guru Pembina sudah memenuhi syarat dalam memberikan bentuk dan program latihan bagi siswa. Guru atau pemmbina adalah fasilitator dalam memberikan latihan ekstrakurikuler bulutangkis. Oleh karena itu guru sangat berpengaruh dalam peningkatan kemampuan pukulan forehand dan smash, metode latihan yang guru gunakan harus bisa menarik anak dan guru harus bisa memotivasi siswa agar semangat dalam mengikuti latihan.

\section{Faktor Sarana dan Prasarana}

Sarana dan prasarana pendidikan jasmani diperlukan dalam pembelajaran pendidikan jasmani di sekolah merupakan hal yang vital. Karena tanpa adanya sarana dan prasarana pembelajaran tidak berjalan. SLB Negeri I Kota Bengkulu mempunyai sarana dan prasarana yang cukup memadai sehingga dapat menunjang proses belajar mengajar pendidikan jasmani dan memberikan motivasi bagi siswa untuk aktif dalam berlatih.

\section{Faktor Lingkungan}

Dukungan dari lingkungan sekitar juga mendorong keberhasilan pembelajaran. Suatu sekolah akan tercipta suasana kondusif apabila lingkungan sekitar ikut berupaya dan menjaga suasana dan kenyamanan sehingga kegiatan belajar mengajar dapat terlaksana dengan baik

\section{Kesimpulan}

Berdasarkan hasil penelitian dan pembahasan diatas dapat diambil beberapa kesimpulan yaitu :

1. Kemampuan servis pendek forehand bulutangkis siswa peserta ekstrakurikuler bulutangkis SLB Negeri I Kota Bengkulu sebagian besar berkategori kurang sebanyak 14 siswa (70\%).

2. Kemampuan smash bulutangkis siswa peserta ekstrakurikuler bulutangkis SLB Negeri I Kota Bengkulu sebagian besar berkategori kurang sekali sebanyak 13 siswa $(65 \%)$

\section{Daftar Pustaka}

Agung Prasetyo (2011). Tingkat kemampuan pukulan forehand dalam permainan bulutangkis siswa peserta ekstrakurikuler SMP N 2 Sleman. Skripsi. Yogyakarta: FIK UNY

Dwiaz Destiyana Purba (2010) Tingkat Kemapuan Pukulan Servis Pendek dan Servis Panjang Bulutangkis Pada Siswa SMP Karangmoncol Purbalingga. Skripsi. Yogyakarta: FIK UNY

Hua Huang \& Aryanto Sugeng (2007) Olahraga Kegemaranku Bulu Tangkis. Klaten: PT. Intan Pariwara

Herman Subarjah. (2000). Bulutangkis. Jakarta: Departemen Pendidikan Dan Kebudayaan. 
Johnson, M.L. (1984). Bimbingan Bermain

Bulutangkis. Jakarta: PT. Mutiara

Sumber Widya.

Kharisma Alfiansyah. (2013). Taktik dan Teknik Permainan Bulutangkis.

Diakses dari

http://fadilkharisma.wordpress.co

m pada tanggal 15 April 2015

Nurhasan. (2001). Tes dan Pengukuran dalam Pendidikan Jasmani.

Jakarta: Direktorat Jendral

Olahraga.

Poole, James. (1986). Belajar Bulutangkis.

Bandung: Pionir Jaya.

Ratih A.P. (2013). Hubungan Ketepatan

Pukulan Servis, Dropshot, dan

Smash dalam Bermain

Bulutangkis. Fakultas Ilmu

Keolahragaan: Universitas

Negeri Yogyakarta.

Syahri, Alhusni. (2007). Gemar Bermain

Bulutangkis. Surakarta: CV'Seti Aji"

Sugiyono. (2009). Metode Penelitian

Kuantitatif, Kualitatif dan R \& D.

Bandung: Alfabeta.

Sukardi. (2011). Metodologi Penelitian

Pendidikan Kompetensi Dan

Praktiknya. Jakarta: Bumi Aksara. 